\title{
Quantitative phase evolution during mechano-synthesis of Ti-Ni-Cu shape memory alloys
}

\author{
Rasool Amini ${ }^{\text {za,*}}$, Fatemeh Alijani ${ }^{\text {a }}$, Mohammad Ghaffari ${ }^{\mathrm{b}}$, Morteza Alizadeh ${ }^{\mathrm{a}}$, Ali Kemal Okyay ${ }^{\mathrm{b}}$ \\ a Department of Materials Science and Engineering, Shiraz University of Technology, 71555-313 Shiraz, Iran \\ ${ }^{\mathrm{b}}$ Department of Electrical and Electronics Engineering, UNAM-Institute of Materials Science and Nanotechnology Bilkent University, Ankara 06800, Turkey
}

\section{A R T I C L E I N F O}

\section{Article history:}

Received 23 April 2012

Received in revised form 18 May 2012

Accepted 20 May 2012

Available online 29 May 2012

\section{Keywords:}

TiNiCu shape memory alloys

Mechanical alloying

Martensitic phase transformation

Amorphous phase

\begin{abstract}
A B S T R A C T
Ti-41Ni-9Cu shape memory alloy was synthesized by mechanical alloying of pure elemental $\mathrm{Ti}$, $\mathrm{Ni}$, and $\mathrm{Cu}$ powders using high-energy ball milling. The qualitative and quantitative phase analyses of the asmilled powders were done by X-ray diffraction (XRD) using Rietveld refinement and the alloys microstructure was studied by scanning electron microscopy (SEM) and high resolution transmission electron microscopy (HRTEM). Concerning the results, by milling evolution, the dissolution of the primary materials occurred at different rates and a considerable amount of the amorphous phase as well as B19'-martensite and B2-austenite was created. The formation of $\mathrm{Ni}$ solid solution was also evidenced prior to its dissolution. It was found that at sufficient milling time, the mechano-crystallization of the amorphous phase occurred and at the end of milling, the B19'-martensite is the dominant phase of the structure.

(c) 2012 Elsevier B.V. All rights reserved.
\end{abstract}

\section{Introduction}

Equiatomic NiTi-based intermetallic compounds are the most important shape memory alloys (SMAs) which exhibit unique properties such as superior shape memory effect (a large recoverable strain up to $8 \%$ ), favorable pseudoelasticity, excellent corrosion resistance, good biocompatibility, and appropriate mechanical properties [1]. Accordingly, these smart materials are widely used in different fields [2] like medical [3,4], dental [5], aerospace, microelectronics, and constructional applications [1-3].

Regularly, NiTi can be crystallized in two different structures; (1) the cubic structure, the high temperature austenite (B2) phase, and (2) the monoclinic structure, the low temperature martensite $\left(B 19^{\prime}\right)$ phase. In this alloying system, the shape memory effect and superelasticity is attributed to the thermal and mechanical transformation of the phases, respectively. The alloy composition, thermomechanical treatment, ternary alloying elements addition, and aging treatment can modify the transformation hysteresis and frequently resulted in a two-stage transformation [6]. For instance, by substituting 10 at.\% $\mathrm{Cu}$ for $\mathrm{Ni}$, the NiTi transforms in two stages: (1) B2-to-B19 (orthorhombic phase) and (2) B19-toB19' $[7,8]$.

In comparison to binary NiTi SMAs, TiNiCu alloys exhibit more favorable properties such as small transformation hysteresis [1,7] and higher corrosion resistance [7,9]. By addition of $\mathrm{Cu}$ to NiTi alloys, not only the composition sensitivity of the transformation

\footnotetext{
* Corresponding author. Tel.: +98 9177148204.

E-mail addresses: amini@sutech.ac.ir, ramini2002@gmail.com (R. Amini).
}

temperature is reduced, but also the aging effect is avoided. The alloy will be transformed in one stage (i.e. B2-to-B19) provided that the $\mathrm{Cu}$-content exceeds 20 at.\%. Under these conditions, due to easy movement of interface during transformation, the transformation hysteresis is sufficiently small compared to B2-to-B19' transformation in binary NiTi alloys. This transformation with small hysteresis is desirable to use in actuators $[1,3,10]$ and sensors [11]. However, exceeding Cu-content from 10 at.\% makes the alloy brittle and reduces its formability [7].

NiTi-based alloys can be produced by variety of methods including vacuum induction melting [12-15], sputtering [16], powder metallurgy [17-19], mechanical alloying (MA) [19-26], and so on. MA is a simple and low cost solid state process suitable for synthesizing the non-equilibrium states, including nanocrystals, amorphous phases, and supersaturated solid solutions. During MA, powder particles are subjected to severe plastic deformation and high density of defects is generated, which promote extensive atomic scale alloying far from equilibrium levels resulting in abnormal phase transformation [27,28].

There have been limited studies in synthesizing the TiNiCu alloys from elemental powders by MA $[20,21]$. In these reports, the amorphization process was studied and the composition range to form the amorphous phase was found to be $10<x<30$ for $\mathrm{Ti}_{50-}$ $\mathrm{Ni}_{50-x} \mathrm{Cu}_{x}$ system. However, no systematic reports are available in the phase transformation of this alloying system during MA. Moreover, the quantitative phase analysis (considering both crystalline and amorphous phases) has not been reported in the alloying system. In the present work, the $\mathrm{Ti}-41 \mathrm{Ni}-9 \mathrm{Cu}$ alloys were synthesized by MA and subsequently the structural and micro- 

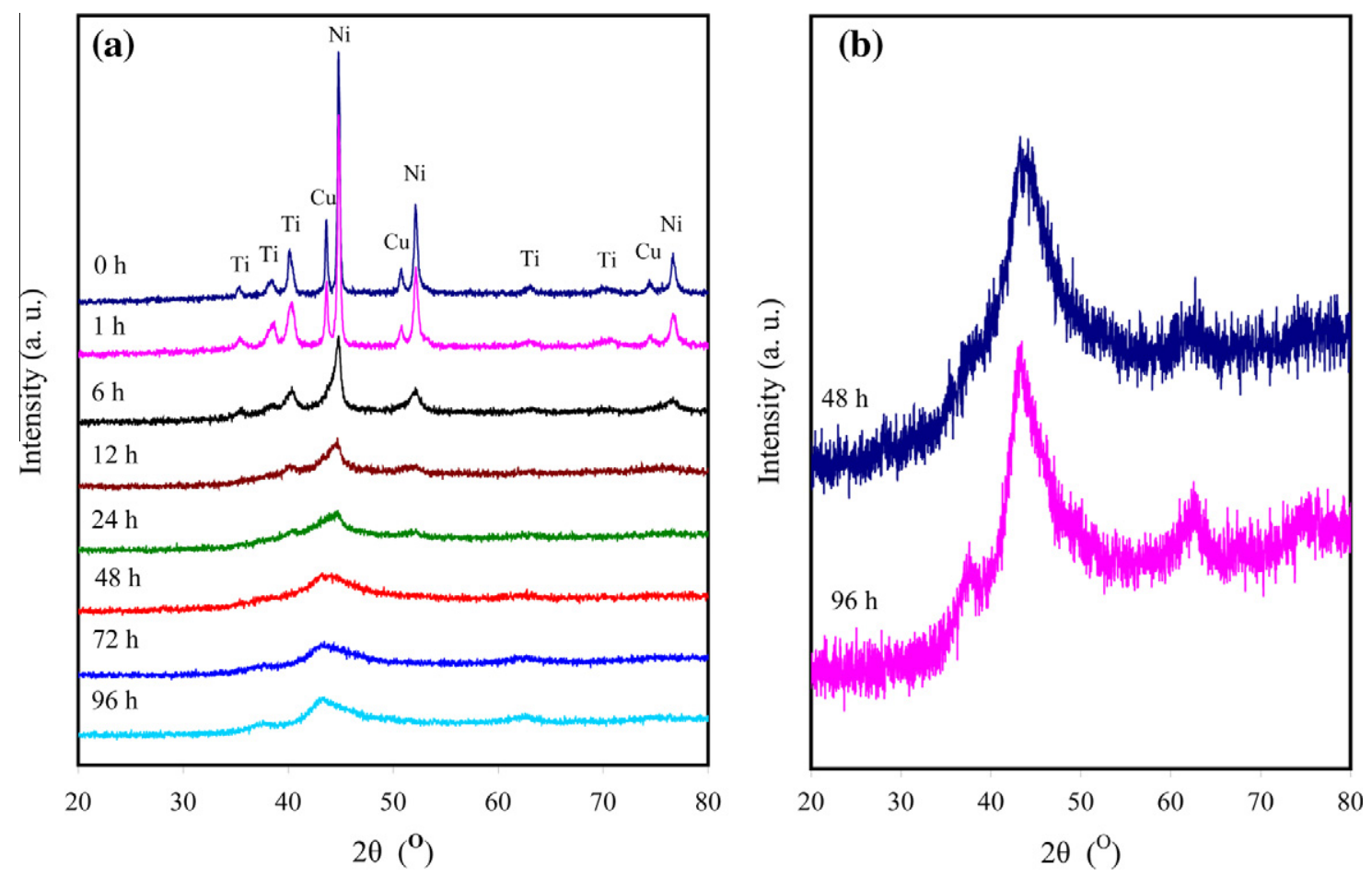

Fig. 1. (a) XRD patterns of the as-milled powders as a function of milling time; (b) a comparison between the XRD pattern of $48 \mathrm{~h}$ and $96 \mathrm{~h}$ milled powders.

structural evolution during the milling cycle was investigated. The main scopes of this study are the determination of the exact mechanism of the alloying process as well as the phase transformation during the milling process. To achieve these aims, the qualitative and quantitative phase analyses were performed on the alloyed powders.

\section{Experimental procedure}

High purity elemental titanium ( $>99 \%$ ), nickel $(>99.5 \%$ ) and copper $(>99.9 \%)$ powders were mixed with the atomic ratio of 50:41:9 (44.56:44.79:10.65 wt.\%) and then mechanically alloyed in a planetary ball mill with tempered steel vials $(90 \mathrm{ml})$ and balls $(5 \times 20 \mathrm{~mm}$ and $7 \times 10 \mathrm{~mm})$ under argon atmosphere. The milling was performed at room temperature with the speed of $450 \mathrm{rpm}$ and the ball-topowder mass ratio of 20:1. The milling process is done in separate stages and powder samples were taken at the end of each stage for structural and microstructural analyses.

The evolution of particles morphology and size was studied by a scanning electron microscope (SEM, FEI, Nova Nanosem 430) and the phase constituent and structural properties of the powders were studied by using powder X-ray diffraction (XRD, Pananalytical, X'pert Pro MPD) with the CuK $\alpha(\lambda=0.154 \mathrm{~nm})$ radiations at $40 \mathrm{kV}$ and $40 \mathrm{~mA}$ at the step time of $0.03 \mathrm{~s}$ and step size of $0.03^{\circ}$ in the $2 \theta$ range of $20-80^{\circ}$. The Rietveld refinement was performed using the MAUD software package version 2.26. A fundamental parameters approach was used for profile fitting. Parameters such as zero point error, sample displacement, scale factor, unit cell parameter, crystallite size, lattice strain, and thermal factor were refined for each phase to minimize the difference between the experimental and calculated patterns. Since the milling process reduces the particles size down to a few tens of nanometers, the micro-absorption correction was not necessary to be considered.

The amorphous phase fraction was also estimated by Rietveld analyzing the XRD profile of a mixture of the as-milled powders and a known amount of fully crystalline Mo powders (as an internal standard). The standard: powders weight ratio of 10:90 was used for this purpose and the amount of amorphous phase was calculated by using the following equation [29].

Amorphous fraction $($ wt. $\%)=\left(1-W_{s} / W_{R}\right) /\left(100-W_{s}\right) \times 10^{4}$

where $W_{S}$ is the weight percentage of the internal standard added to the powders and $R_{\mathrm{S}}$ is its concentration estimated by Rietveld refinement of the XRD results.

Finally, to investigate the microstructural features of the as-milled powders, selected powder particles were dispersed in ethanol, dropped down to a copper grid, and then characterized by a high-resolution transmission electron microscope (HRTEM, FEI, Tecnai G2 F30).

\section{Results and discussion}

\subsection{Structural characterization}

Fig. 1a shows the XRD pattern of the as-milled powders at various milling time. As it can be seen from the figure, by starting the milling process, the peaks sharpness and broadening of the starting materials are reduced and increased, respectively. By progression of milling, the alloying process is done and the peaks of the initial materials are vanished in which the $\mathrm{Cu}$ and $\mathrm{Ti}$ are disappeared faster than $\mathrm{Ni}$ and are completely eliminated after $24 \mathrm{~h}$ of milling. Based on the broadening of the XRD results of the as-milled powders, particularly $48 \mathrm{~h}$, the development of nano-size structures, introduction of high amount of lattice strain, and also the existence of high quantity of amorphous phase are evident. Comparing the XRD patterns of $48 \mathrm{~h}$ and $96 \mathrm{~h}$ powders (Fig. 1b), indicated that a crystallization process occurred during this milling period. During the milling cycle, by applying the strong extra energy to the alloyed powders and possibly temperature increasing and also powder contamination [28], the mechano-crystallization process can occur, although the exact reason of the phenomenon is not clearly indicated.

More focus on the XRD results indicated that by increasing the milling time, due to dissolution of $\mathrm{Cu}$ and $\mathrm{Ti}$ in the Ni lattice and consequently solid solution formation, the $\mathrm{Ni}$ peaks are displaced towards lower angles. The variation of Ni lattice parameter with milling time is shown in Fig. 2. It can be observed that at first stages of milling, because of severe plastic deformation and disordering, the Ni lattice parameter is decreased (which is compatible with Ref. [30]) and then, owing to dissolution of $\mathrm{Cu}$ and especially $\mathrm{Ti}$ in the Ni lattice, it is increased.

Fig. 3 depicts the variation of crystallite size and lattice strain of the present phases as a function of milling time. As it was expected, by milling evolution, the nano-crystallization was developed and the high amount of lattice strain was established. Concerning the results, the rate of crystallite size reduction and r.m.s microstrain increasing of primary and final phases is reduced by milling development. 


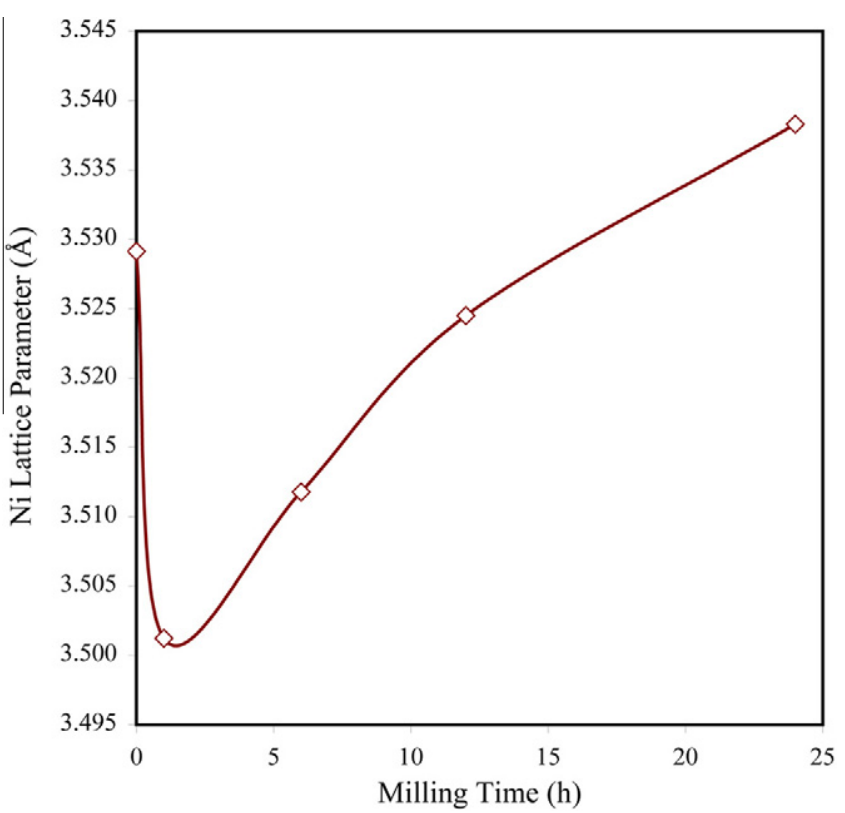

Fig. 2. The variation of Ni lattice parameter as a function of milling time. Increasing in the lattice parameter is attributed to the formation of solid solution.

The variation of phase content by milling time is listed in Table 1 . As can be seen, by starting the milling process, the quantity of elemental powders decreases with different rates in which $\mathrm{Cu}$ and $\mathrm{Ti}$ are totally dissolved into the structure after $12 \mathrm{~h}$ and $24 \mathrm{~h}$ of milling, respectively. Furthermore, the formation of B19' martensite and B2 austenite phases are indicated. That is, although the stress-induced martensite $\left(\mathrm{B} 19^{\prime}\right)$ is formed due to severe plastic deformation induced during milling, the high temperature $B 2$ phase is also created due to temperature rising during MA. By comparing the lattice parameter of the B2 phase $(3.102 \AA)$ with that of B2 phase created in Ti-50 at.\% Ni al-
Table 1

The variation of phase content by milling time.

\begin{tabular}{rllllll}
\hline \multirow{2}{*}{ Milling time (h) } & \multicolumn{6}{l}{ Weight percentage (wt.\%) } \\
\cline { 2 - 7 } & $\mathrm{Ni}$ & $\mathrm{Ti}$ & $\mathrm{Cu}$ & $\mathrm{B} 19^{\prime}$ & $\mathrm{B} 2$ & Amorphous \\
\hline 1 & $41(3)$ & $33(3)$ & $5(1)$ & - & - & $21(2)$ \\
6 & $37(3)$ & $14(2)$ & $4(0.5)$ & - & - & $45(3)$ \\
12 & $14(2)$ & $3(0.5)$ & $2(0.5)$ & $16(2)$ & $9(1)$ & $56(4)$ \\
24 & $4(0.5)$ & $1(0.5)$ & - & $20(2)$ & $11(1)$ & $64(4)$ \\
48 & - & - & - & $22(2)$ & $12(1)$ & $66(4)$ \\
72 & - & - & - & $30(3)$ & $14(2)$ & $56(4)$ \\
96 & - & - & - & $31(3)$ & $21(2)$ & $48(3)$ \\
\hline
\end{tabular}

Error value $(X): \pm X$ wt.\%.

loy systems (3.015 $\AA$ ) [13,31], the formation of disordered B2 phase, due to dissolution of $\mathrm{Cu}$ into the structure is obvious.

According to the XRD results, it is evident that an amorphous phase is formed at initial milling times and it grew considerably by progression of milling up to $48 \mathrm{~h}$. On the other hand, by milling development to $72 \mathrm{~h}$ and $96 \mathrm{~h}$, because of mechano-crystallization of the amorphous phase to the crystalline B19' and B2 phases, its amount is reduced considerably.

Based on the stoichiometric quantity of the elements in the crystalline phases and the composition of the powders, the amount of the elements in the amorphous phase can be estimated. Fig. 4 illustrates the distribution of $\mathrm{Ni}$, $\mathrm{Ti}$ and $\mathrm{Cu}$ elements in the amorphous phase at different milling times. Since the $\mathrm{Cu}$ atoms can be randomly dissolved into the Ni lattice without any measurable change in Ni lattice parameter [13,31], the calculation of the exact amount of the $\mathrm{Cu}$ in the amorphous phase is impractical. Considering the fact, a range of elements weight fraction (from minimum to maximum) is reported prior to total dissolution of $\mathrm{Ni}$ into the structure. The results shows that the high fraction of $\mathrm{Ti}$ and $\mathrm{Cu}$ precursors are dissolved into the amorphous phase at the initial stages of milling and by milling progression the amount of $\mathrm{Ni}$ in the amorphous phase is increased and after sufficient milling time (e.g. $48 \mathrm{~h}$ ), the composition of the amorphous phase reaches the stoichiometric
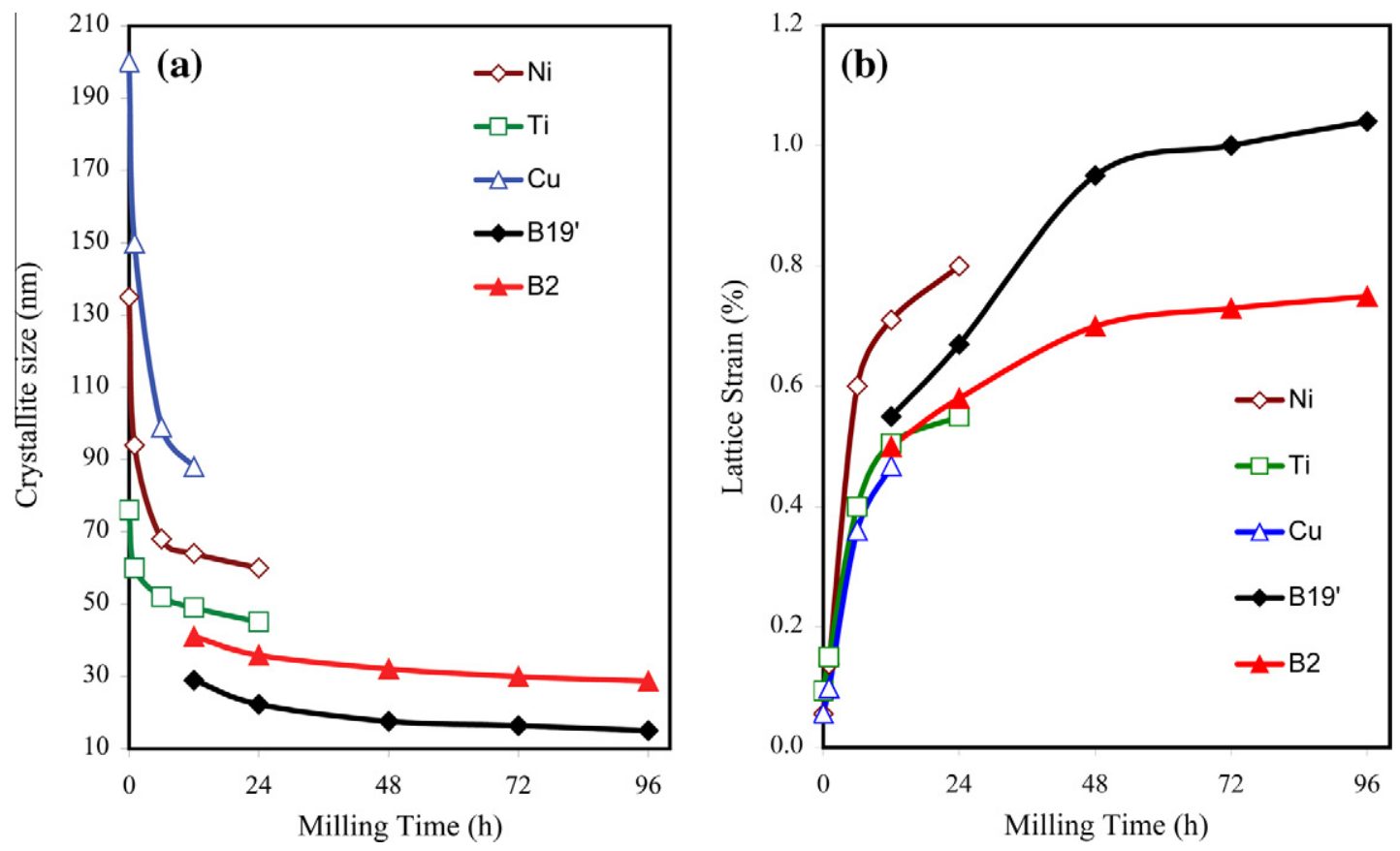

Fig. 3. The variation of (a) crystallite size and (b) lattice strain of the present crystalline phases by milling time. 


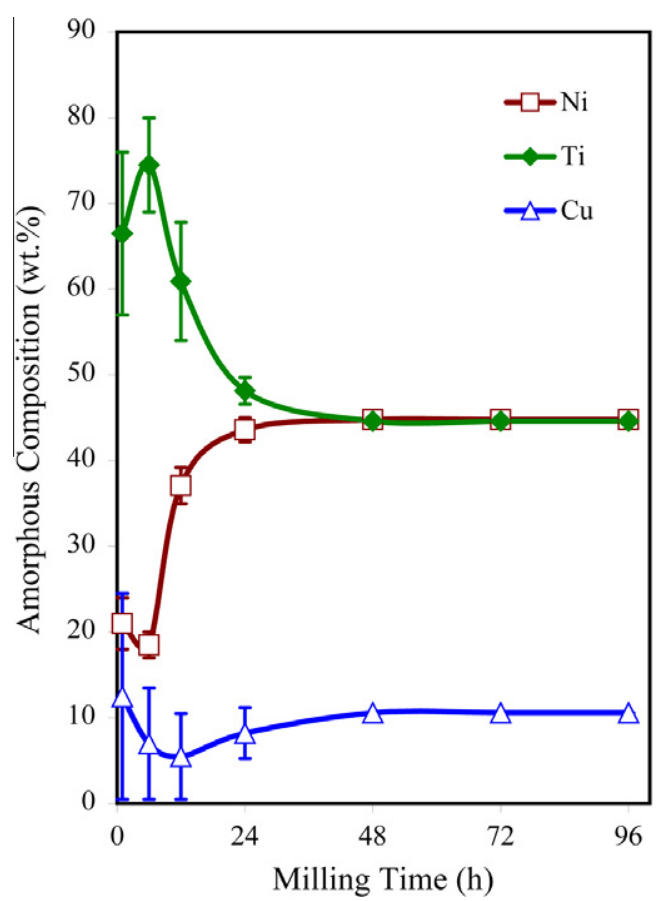

Fig. 4. Distribution of alloying elements in the amorphous phase at different milling times.

composition of TiNiCu compound. These conditions favor the transformation of the amorphous phase to the more stable phases namely B19' and B2. Comparing the results of Table 1 and Fig. 4 reveals that, at initial milling intervals (up to $48 \mathrm{~h}$ ), the B19' and B2 phases are almost produced directly from the primary materials and subsequently created from the amorphous phase after sufficient milling times (e.g. $72 \mathrm{~h}$ and $96 \mathrm{~h}$ ).

\subsection{Microstructural evaluation}

\subsubsection{SEM observations}

Fig. 5 shows the SEM image of the selected as-milled powders. Concerning the results, in the early stages of milling (e.g. $1 \mathrm{~h}$ ), due to high surface energy of fine and ductile particles and consequently the domination of cold welding and agglomeration, the plate-like morphology with a wide range of particle size is developed (Fig. 5a). After $6 \mathrm{~h}$ of milling, the maximum cold welding and inhomogeneity in the particle size existed. At this time intervals, a composite lamellar structure of the constituents were formed and by continuation of milling, the refinement of the layered structure occurred (Fig. 5b). By milling development, the coarse particles fracturing as well as fine particles cold welding occurred simultaneously and due to amorphous phase increasing (indicated by the XRD results), the brittleness of the powders is raised; consequently the particles size is noticeably reduced and, their morphology tends to be semi-spherical with the narrow range of size distribution (Fig. 5c). At final stages of milling (e.g. $72 \mathrm{~h}$ ) because of mechano-crystallization of the amorphous phase, the ductility of powders is increased; therefore, the cold welding process overcomes the fracture mechanisms and the powder particle size increases (Fig. 5d).

\subsubsection{TEM studies}

Fig. 6 shows the HRTEM and the corresponding selected area diffraction (SAD) pattern of the powders milled for $96 \mathrm{~h}$. As it can be clearly seen in the HRTEM image, the structure of the powders contains a combination of crystalline and amorphous phases confirmed by the continuous polycrystalline rings and amorphous halo
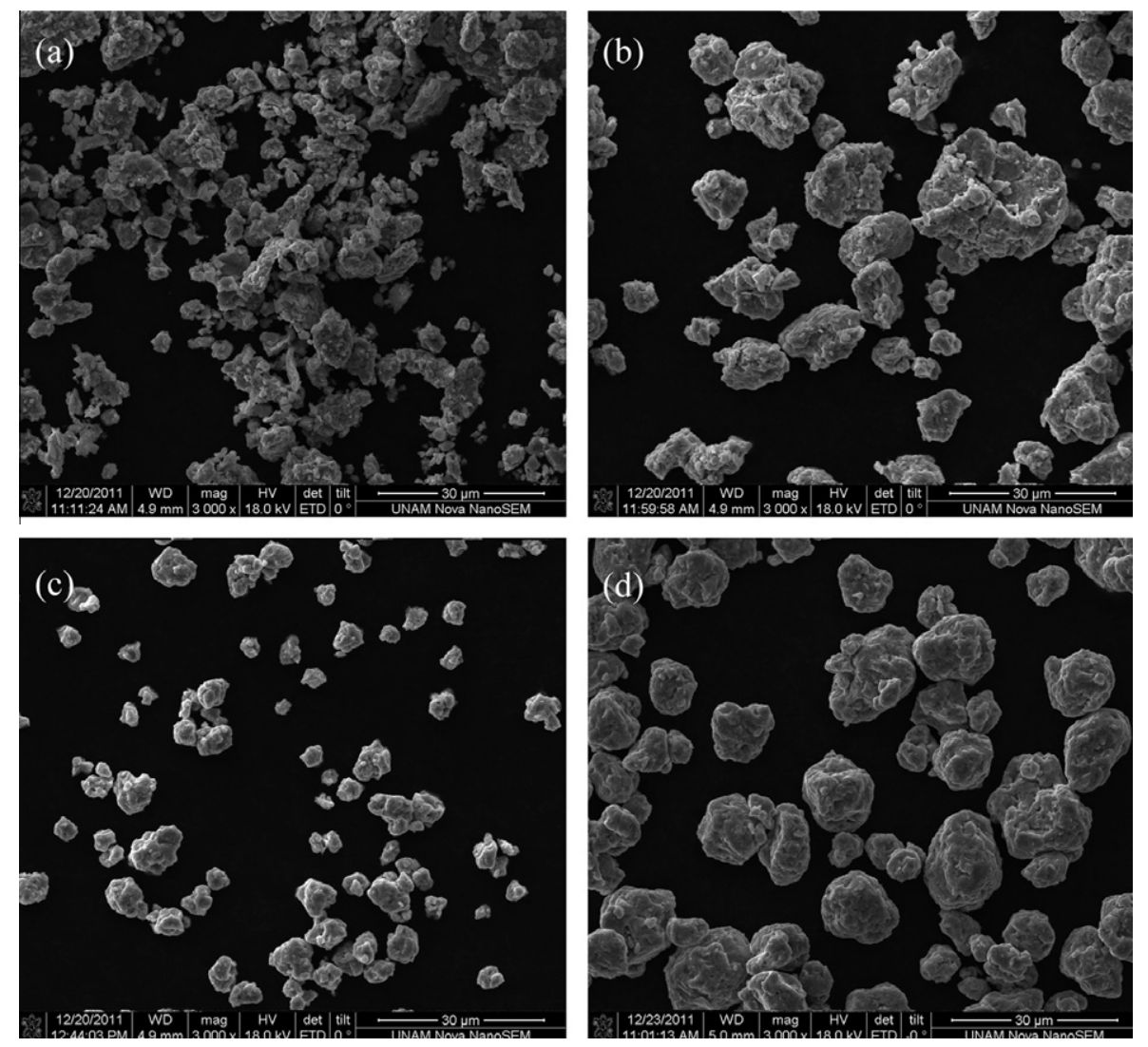

Fig. 5. SEM micrograph of the as-milled powders (a) 1 h; (b) 6 h; (c) 24 h; (d) 72 h. 

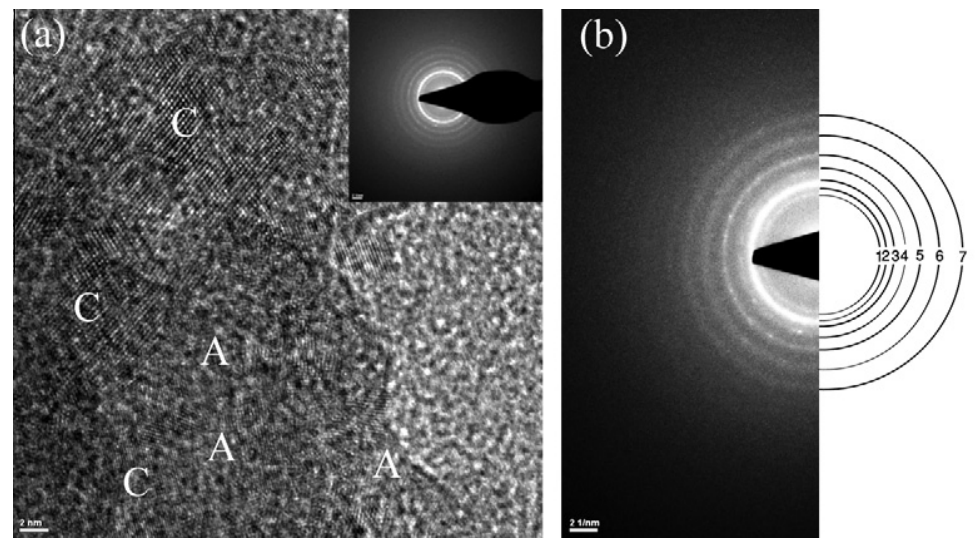

\begin{tabular}{|c|c|c|}
\hline \multirow{2}{*}{ Circle No. } & \multicolumn{2}{|c|}{ (h k l) } \\
\hline & B19' & B2 \\
\hline 1 & $\left(\begin{array}{lll}0 & 2 & 0\end{array}\right)$ & - \\
\hline 2 & $\left(\begin{array}{lll}1 & 1 & 1\end{array}\right)$ & $\left(\begin{array}{lll}1 & 1 & 0\end{array}\right)$ \\
\hline 3 & $\begin{array}{l}\left(\begin{array}{lll}0 & 0 & 2\end{array}\right) \\
\left(\begin{array}{llll}0 & 2 & 1\end{array}\right)\end{array}$ & - \\
\hline 4 & $\left(\begin{array}{lll}1 & 2 & 1\end{array}\right)$ & - \\
\hline 5 & $\begin{array}{l}\left(\begin{array}{lll}2 & 1 & 0\end{array}\right) \\
\left(\begin{array}{llll}1 & 1 & 3\end{array}\right)\end{array}$ & $\left(\begin{array}{lll}2 & 0 & 0\end{array}\right)$ \\
\hline 6 & $\begin{array}{ll}\left(\begin{array}{lll}2 & 1 & 2\end{array}\right) \\
\left(\begin{array}{lll}1 & 3 & 0\end{array}\right)\end{array}$ & $\left(\begin{array}{lll}2 & 1 & 1\end{array}\right)$ \\
\hline 7 & $\left(\begin{array}{lll}1 & 3 & 2\end{array}\right)$ & - \\
\hline
\end{tabular}

Fig. 6. (a) HRTEM images of $96 \mathrm{~h}$ milled powders indicated the amorphous, A, and crystalline, C, parts of the structure; (b) SAD pattern analysis of $96 \mathrm{~h}$ milled powders.

pattern of the SAD patterns. In order to determine the origin of reflection rings, the SAD pattern of the $96 \mathrm{~h}$ powder was interpreted and the results were indicated in Fig. 6b. Based on the results, although most of the rings are related to the martensiteB19' structure, the existence of B2 structure is also evident.

\section{Conclusions}

In the present work, the amorphous/nanocrystalline $\mathrm{Ti}-41 \mathrm{Ni}-$ $9 \mathrm{Cu}$ alloys were prepared by mechanical alloying of the elemental powders and their structural and microstructural properties were evaluated. According to the results, it can be concluded that:

(1) During the milling cycle, nanocrystallization rapidly occurred and the high amount of micro-strains and lattice defects were created.

(2) By milling initiation, the elemental powders were becoming dissolved into the structure by different rate and a significant amount of amorphous phase was formed in addition to the formation of B19'-martensite and B2-austenite phases.

(3) The formation of supersaturated solid solution of $\mathrm{Ti}$ and $\mathrm{Cu}$ in $\mathrm{Ni}$ was verified by increasing the Ni lattice parameter prior to its complete dissolution.

(4) By milling progression, the amount of the amorphous phase was increased considerably and after sufficient milling time, the composition of the amorphous phase reached at the stoichiometric composition of $\mathrm{TiNiCu}$ and the mechano-crystallization of the amorphous phase occurred and its amount was reduced by milling development.

(5) The nanocrystalline B19' and B2 phases was almost created directly from the primary materials at initial stages of milling and subsequently formed from the amorphous phase after sufficient milling times. That is, the quantity of the B19' and B2 phases were continuously grown by milling progression. It was estimated by quantitative XRD analysis and also confirmed by SAD pattern of TEM.
(6) By milling evolution, the powders morphology was changed from plate-like to semi-sphere and the average particles size was initially increased, then reduced, and afterward reincreased. Moreover, the particles size distribution was changed from wide to narrow ranges.

\section{References}

[1] K. Otsuka, C.M. Wayman, Shape Memory Materials, Cambridge University Press, Cambridge, 1998

[2] J.V. Humbeeck, Mater. Sci. Eng. A273-A275 (1999) 134-148.

[3] D.C. Lagoudas, Shape Memory Alloys Modeling and Engineering Applications, Springer, Texas, 2008

[4] A.R. Pelton, D. Stöckel, T.W. Duerig, Mater. Sci. Forum 327-328 (2000) 63-70.

[5] S.A. Thompson, Int. Endod. J. 33 (2000) 297-310.

[6] K. Otsuka, X. Ren, Prog. Mater. Sci. 50 (2005) 511-678.

[7] T.H. Nam, T. Saburi, K. Shimizu, Mater. Trans. JIM 31 (1990) 959-967.

[8] P.L. Potapov, A.V. Shelyakov, D. Schryvers, Scr. Mater. 44 (2001) 1-7.

[9] W. Haider, N. Munroe, C. Pulletikurthi, P.K. Singh Gill, S. Amruthaluri, J. Mater. Eng. Perform. 18 (2009) 760-764.

[10] W. Predki, A. Knopik, B. Bauer, Mater. Sci. Eng., A 481-482 (2008) 598-601.

[11] Y. Huajun, X. Xia, Rare Met. 28 (2009) 63-76.

[12] F.J.J. Van Loo, G.F. Bastin, A.J.H. Leenen, J. Less-Common Met. 57 (1978) 111-121.

[13] T. Fukuda, T. Saburi, T. Chihara, Y. Tsuzuki, Mater. Trans. 36 (1995) 1244-1248.

[14] X.L. Meng, Y.F. Zheng, W. Cai, L.C. Zhao, J. Alloys Compd. 372 (2004) 180-186.

[15] L. Zhang, C. Xie, Ji Wu, Mater. Sci. Eng., A 438-440 (2006) 905-910.

[16] Y. Xu, X. Huang, A.G. Ramirez, J. Alloys Compd. 480 (2009) L13-L16.

[17] T. Goryczk, J. Van Humbeeck, J. Achieve. Mater. Manuf. Eng. 17 (2006) 65-68.

[18] T. Goryczk, J.V. Humbeeck, J. Alloys Compd. 456 (2008) 194-200.

[19] M. Valeanu, M. Lucaci, A.D. Crisan, M. Sofronie, L. Leonat, V. Kuncser, J. Alloys Compd. 509 (2011) 4495-4498.

[20] T.H. Nam, S.G. Hur, I.S. Alan, Met. Mater. 4 (1998) 61-66.

[21] B.S. Murty, S. Ranganathan, M. Mohan Rao, Mater. Sci. Eng., A 149 (1992) 231-240.

[22] A. Takasaki, Phys. Status Solidi A 169 (1998) 183-191.

[23] M. Zhu, M. Qlt, A.Q. He, H.X. Sup, W.G. Liu, Acta Metall. Mater. 42 (1994) 1893-1899.

[24] S. Chen, Y. Zhou, Y. Li, J. Mater. Sci. Technol. 13 (1997) 86-90.

[25] Y.W. Gu, C.W. Goh, L.S. Goi, C.S. Lim, A.E.W. Jarfors, B.Y. Tay, M.S. Yong, Mater. Sci. Eng., A. 392 (2005) 222-228.

[26] S. Kanchibhotla, N. Munroe, T. Kartikeyan, J. Mater. Sci. 40 (2005) 5003-5006.

[27] C. Suryanarayana, Prog. Mater. Sci. 46 (2001) 1-184.

[28] C. Suryanarayana, Mechanical Alloying and Milling, Marcel Dekker, New York, 2004.

[29] R. Amini, M.J. Hadianfard, E. Salahinejad, M. Marasi, T. Sritharan, J. Mater. Sci. 44 (2009) 136-148.

[30] S. Tria, O. Elkedim, R. Hamzaoui, X. Guo, F. Bernard, N. Millot, O. Rapaud, Powder Technol. 210 (2011) 181-188.

[31] M. Es-Souni, M. Es-Souni, H.F. Brandies, Biomaterials 22 (2001) 2153-2161. 